\title{
A multi-kinase inhibitor APG-2449 enhances the antitumor effect of Ibrutinib in esophageal squamous cell carcinoma via EGFR/FAK pathway inhibition
}

\author{
Qiu-Yun Luo
}

Sun Yat-sen University Cancer Center

Su-Na Zhou

Sun Yat-sen University Cancer Center

Wen-Tao Pan

Sun Yat-sen University Cancer Center

Jian Sun

Sun Yat-sen University Cancer Center

\section{Li-Qiong Yang}

Sun Yat-sen University Cancer Center

\section{Lin Zhang}

Sun Yat-sen University Cancer Center

Miao-Zhen Qiu ( $\square$ qiumzh@sysucc.org.cn )

Sun Yat-sen University Cancer Center https://orcid.org/0000-0002-4774-6235

Da-Jun Yang

Sun Yat-sen University Cancer Center

\section{Research}

Keywords: APG-2449, FAK, Ibrutinib, EGFR, ESCC, combination therapy

Posted Date: July 6th, 2020

DOl: https://doi.org/10.21203/rs.3.rs-39993/v1

License: (9) This work is licensed under a Creative Commons Attribution 4.0 International License. Read Full License

Version of Record: A version of this preprint was published at Biochemical Pharmacology on January 1st, 2021. See the published version at https://doi.org/10.1016/j.bcp.2020.114318. 


\section{Abstract}

Background Esophageal squamous cell carcinoma (ESCC) is one of the most common types of cancer in China, with poor prognosis and lack of effective targeted therapy. It has been reported that ibrutinib possesses anticancer activity in ESCC with MYC and/or ERBB2 amplified. Here we explored the synergistic antitumor effect of a novel multi-kinase inhibitor APG-2449 with ibrutinib in ESCC and clarified the mechanism of the combination effect. Methods Cancer cells viability was determined by CCK- 8 assay. Western blot was used to detect the expression of related proteins. Xenograft models in nude mice were established to explore the roles of APG-2449 and ibrutinib. Results We found that APG-2449 exerted antitumor effect in ESCC through FAK blocking. APG-2449 combined with ibrutinib showed synergistic inhibition of cell viability in ESCC cell lines. APG-2449 combined with ibrutinib dramatically inhibited the proliferation and migration of ESCC cells. Furthermore, we observed that ibrutinib combined with APG2449 could induce more cancer cells arrested in the G1/S phase and apoptosis. In terms of mechanism, ibrutinib alone could inactive EGFR and its downstream signaling of MEK/ERK. The combination therapy of APG-2449 and ibrutinib could significantly down-regulate the phosphorylation level of MEK / ERK and AKT. In ESCC xenotransplantation models, single therapy with either ibrutinib or APG-2449 was equivalent in delaying tumor growth, while the combination therapy suppressed tumor growth more significantly. Conclusion Our data strongly suggest that the combination therapy of APG-2449 and ibrutinib can provide an effective therapeutic strategy for treating ESCC, which deserved further clinical investigation.

\section{Introduction}

Esophageal squamous cell carcinoma (ESCC) is one of the most common subtypes of esophageal cancer and is highly prevalent in China[1]. It is presently the fourth leading cause of cancer mortality[24]. Currently, endoscopic resection, surgery and chemotherapy are the major treatments for ESCC[5]. However, as current therapies have limited efficacy in advanced ESCC [6, 7], this warrants additional need for novel therapeutic approaches.

Focal adhesion kinase (FAK) is a protein tyrosine kinase that is an important downstream effector of integrin, regulating the adhesion, movement, proliferation and survival of various human cancer cells[8, 9]. Activated FAK promotes tumor development and metastasis by stimulating its downstream signaling pathways such as PI3K/AKT, N-WASP[10]. Therefore, FAK has become a potential therapeutic target for many cancers $[11,12]$. Previous studies have found that FAK overexpression was tightly related to esophageal cancer cell differentiation, tumor invasion and metastasis[13]. Approximately $60 \%$ of patients with esophageal cancer have high expression of FAK, which is related to a low five-year survival rate[14]. However, there are still no successful FAK inhibitors available for the treatment of esophageal cancer.

Ibrutinib, an irreversible Bruton's tyrosine kinase (BTK) inhibitor, was approved by the FDA for the treatment of mantle cell lymphoma (MCL)[15], diffuse large B-cell lymphoma (DLBCL)[16]and chronic lymphocytic leukemia (CLL)[17]. Recently, novel indications of BTK inhibitors beyond hematological malignancies have been revealed[18]. For ESCC, Christopher $\mathrm{J}$ et al. showed that ibrutinib had a 
significant antitumor effect on esophageal cancer patients with MYC and/or ERBB2 amplified[19]. This discovery provides a novel therapeutic strategy for esophageal cancer and is worthy of further in-depth research and exploration of other reasonable combination with ibrutinib, which can broaden the application of BTK inhibitors in esophageal cancer and other solid tumors. The previous researches have demonstrated that ibrutinib elicited antitumor effect in multiple solid tumors, including non-small cell lung cancer, breast cancer and so on[20,21]. And the major action mechanism of ibrutinib in disease mentioned above is suppressing the receptor tyrosine kinase EGFR or ERBB2. EGFR is considered as a potential therapeutic target for ESCC, however, the efficacy of current EGFR-targeting small-molecule inhibitors for ESCC remain unfavorable. It has been reported that Src family kinases (SFK) and FAK mediated resistance to EGFR tyrosine kinase inhibitors (TKI) by sustain AKT and mitogen-activated protein kinase (MAPK) pathway signaling in EGFR-mutant lung cancer[22]. We hypothesized that the antitumor effect of ibrutinib in ESCC may also through EGFR blocking, and combined with FAK inhibition may exert better efficacy.

In the present study, we found that APG-2449, a novel oral multi-kinase inhibitor developed by Ascentage Pharma Group Inc (Taizhou, China), which is remain in preclinical investigation, could inhibit ESCC cells by blocking FAK. And we further uncovered that the combination effect of ibrutinib with APG-2449 and uncover the underlying mechanism for combination treatment is through EGFR and FAK signaling pathways inhibition, therefore to provide a more effective strategies for ESCC treatment.

\section{Materials And Methods}

\section{Cell lines and cell culture}

Human ESCC cell lines TE-10, TE-1, YES-2, KYSE-520, KYSE-510, KYSE-150 were purchased from Cobioer Biosciences Co.LTD (Nanjing, China). All these cell lines were identified by genomic short tandem repeat (STR) profile detection, which providing by Cobioer Biological Technology. All cells were cultured in RPMI1640 medium containing $10 \%$ fetal bovine serum, $100 \mathrm{lU} / \mathrm{mL}$ penicillin and $100 \mathrm{mg} / \mathrm{mL}$ streptomycin and in a humidified atmosphere containing $5 \% \mathrm{CO}_{2}$ at $37^{\circ} \mathrm{C}$. A test for mycoplasma in cells was carried out before all experiments were performed.

\section{Regents and antibodies}

A novel multikinase inhibitor APG-2449 was kindly provided by Ascentage Pharma Group Inc (Taizhou, China). BTK inhibitors Acalabrutinib and ibrutinib were purchased from Selleck Chemicals (Houston, USA). All compounds were dissolved in dimethylsulfoxide (DMSO; Sigma Aldrich, MO, USA) at a stock concentration of $40 \mathrm{mM}$, stored at $-20^{\circ} \mathrm{C}$. The final concentration of DMSO to dilute compound in culture media did not exceed $0.1 \%$. The antibodies against EGFR, p-EGFR (Tyr1068), FAK, p-FAK (Tyr397), AKT, pAKT (Ser473), p-c-myc, ERK, p-ERK and p-MEK were purchased from Cell Signaling Technology (MA, USA). The antibody against BTK and $\beta$-tubulin were purchased from Immunoway (Texas, USA). The 
antibody against GAPDH was purchased from ABGENT (San Diego, USA). The secondary anti-mouse and anti-rabbit antibodies were purchased from Santa Cruz Biotechnology.

\section{Cell proliferation detection}

Cell viability was determined using Cell Counting Kit-8 (Dojindo, Japan) according to the manufacturer's instructions. Briefly, ESCC cells were seeded at 3000 to 4000 cells/well in 96-well plates for 72 hours in the presence of DMSO, APG-2449, ibrutinib or combination therapy of APG-2449 and ibrutinib. After 72 hours, CCK-8 reagent ( $10 \mu \mathrm{L} /$ well) was added and incubated at $37^{\circ} \mathrm{C}$ for $1-2$ hours and their absorbance readings were taken at $450 \mathrm{~nm}$. Their IC50 values were calculated by using GraphPad Prism version 6.0.0 (GraphPad Software, San Diego, California USA) for Windows.

\section{Colony formation assay}

ESCC cells were seeded in a 6-well plate at approximately 500 cells/well and were treated with a single drug or combination of drugs, a negative control group was added with an equal volume of DMSO. Fresh culture medium was replaced every 3-4 days. After 14 days, the cells were fixed in methanol and stained with $0.5 \%$ crystal violet for 15 minutes at room temperature, after which the number of colonies were counted.

\section{Transwell assay}

The ESCC cells $\left(1 \times 10^{5}\right.$ cells) were suspended in $200 \mu \mathrm{L}$ medium containing no FBS with indicated drugs and were then aspirated into a transwell chamber (PC membrane, pore size $8.0 \mu \mathrm{m}$, Corning, NY, USA). The transwell chamber was placed in a 24-well plate containing $750 \mathrm{uL}$ of $50 \% \mathrm{FBS}$ culture medium. After 24-30 hours, the chamber was taken out, fixed in methanol and stained with $0.5 \%$ crystal violet for 15 minutes. Then, the chambers were dried at room temperature and imaged using a microscope.

\section{Wound healing assay}

Wound healing assays were applied to test cell migration ability. ESCC cells were seeded in six-well plates and fused to $100 \%$. Then, a $200-\mu \mathrm{L}$ pipette tube was used to create an artificial wound. Fresh medium containing $1 \%$ FBS with indicated chemicals was added. The wound closure was photographed immediately and 24 hours later under a microscope. The Image $\mathrm{J}$ software was used to calculate the distance between cells

\section{Cell cycle detection}

For cell cycle analysis, ESCC cells were plated at $4 \times 10^{5}$ cells / well in 6-well plates and treated with indicated chemicals for 24 hours. The cells were then harvested and fixed overnight in $70 \%$ ethanol at 4 ${ }^{\circ} \mathrm{C}$ and stained with propidium iodide (KeyGen Biotech, Nanjing, China). DNA content was analyzed using an ACEA NovoCyte ${ }^{T M}$ flow cytometer (ACEA Biosciences Inc. China). 


\section{Cell apoptosis assays}

ESCC cells were plated at $1 \times 10^{5}$ cells/well in 12-well plates and treated with indicated chemicals for 72 hours. The cells were then collected and stained with Annexin V-FITC/PI according to the instructions of the Apoptosis Detection Kit (Sizhengbo Biotechnology, Beijing, China). Cell apoptosis were detected using an ACEA NovoCyte ${ }^{T M}$ flow cytometer (ACEA Biosciences Inc. China).

\section{Western blot analysis}

Cells were treated with DMSO and indicated dose of drugs for $24 \mathrm{~h}$, and then harvested and washed once with pre-cooled PBS. The cells were lysed on ice using a $1 x$ cell lysis buffer containing $1 \%$ protease inhibitor (PMSF), 1\% phosphokinase inhibitor for 30 minutes, centrifuged at $12000 \mathrm{rpm}$ for 15 minutes at $4{ }^{\circ} \mathrm{C}$, and the supernatant protein lysate was collected. Protein concentration was measured by a BCA kit. Cellular protein lysates were separated using 8-12\% SDS-PAGE gel and then transferred to a PVDF membrane. The PVDF membrane was blocked with 5\% BSA buffer for 1 hour at room temperature and then incubated with indicated primary antibody at $4{ }^{\circ} \mathrm{C}$ overnight. 1xTBST (washing buffer) washing the membrane 3 times with 10 minutes each time. The protein membrane was incubated with secondary antibody for 1 hour at room temperature and washed with 1xTBST for 3 times for 10 minutes each time. Signal generation and detection were performed using an ECL chemiluminescence hypersensitive colorimetric kit and a chemiluminescent imaging system

\section{Proteome profiler analysis}

The Human Phospho-Kinase Array Kit (\#ARY003B, R\&D Systems, Wiesbaden-Nordenstadt, Germany) was applied to detect the levels of 43 specific kinase phosphorylation sites in KYSE-150 cells with different treatments. For the preparation of total protein extracts, $1 \times 10^{6} / \mathrm{mL}$ KYSE- 150 cells were seeded in $6 \mathrm{~cm}$ dish. After $24 \mathrm{~h}$, the cells were treated DMSO, $2 \mu \mathrm{M}$ APG-2449, $1 \mu \mathrm{M}$ ibrutinib and combination treatment for $24 \mathrm{~h}$. The preparation of cellular extracts and the proteome profiling were carried out according to the manufacturer's instructions. Briefly, the membranes were incubated with blocking buffer before the experiment. The cell lysates were diluted in blocking buffer with a total protein amount of $600 \mu \mathrm{g}$ then incubated overnight with detected membranes. After several washing steps, the membranes were incubated in the provided detection antibody cocktail for $2 \mathrm{~h}$, then washed again and incubated for 30 minutes in streptavidin-horseradish peroxidase (HRP). The unbound HRP antibody was washed away, and then the signal is analyzed with a chemiluminescent substrate and detected with an X-ray array. For quantification, the signal was analyzed using ImageJ.

\section{Animal experiment}

KYSE-150 and KYSE-520 xenograft models were used to evaluate the anti-tumor effects of APG-2449 in vivo. Four-week-old female BALB/c athymic nude mice were purchased from Beijing Vital River Laboratory Technology Co. Ltd. KYSE-150 and KYSE-520 cells $\left(5 \times 10^{6}\right)$ suspended in $100 \mu \mathrm{L}$. Cold PBS were subcutaneously injected into the dorsal flank of the mice. When the tumor volume reached 
approximately $100 \mathrm{~mm}^{3}$, the mice were randomly assigned into different groups. For APG-2449 single agent in vivo experiment, the mice were subjected to treatment with APG-2449 (delivered orally at 50 $\mathrm{mg} / \mathrm{kg}, 100 \mathrm{mg} / \mathrm{kg}$, once a day) or vehicle control (20\%PG/80\%NaH2PO4) for two weeks.

For the combination experiment, KYSE-150 xenograft models were used. Seven mice per group were assigned to administrate with vehicle control, APG-2449 (100 mg/kg/day; by oral), ibrutinib $(25 \mathrm{mg} / \mathrm{kg} /$ day; intraperitoneally), or both for two weeks. Tumor sizes and animal weights were recorded two times per week and tumor volumes were calculated as $V(\mathrm{~mm} 3)=1 / 2 \times$ (length $\times$ width2). All animal experiments were performed under the guidance of Sun Yat-Sen University Committee for Use and Care of Laboratory Animals and were approved by the animal experimentation ethics committee.

\section{Statistical analysis}

Statistical analyses were performed in GraphPad Prism version 6.0.0 for Windows (GraphPad Software, San Diego, California USA). Unless indicated, all results were presented as the mean \pm SD of three independent experiments. Differences between two groups were analyzed using unpaired sample t-test. Comparison among more than two groups was analyzed by One-way ANOVA and Two-way ANOVA. Combination Index $(\mathrm{Cl})$ was calculated using the CalcuSyn software (BIOSOFT, MO, USA). $p<0.05$ was considered as statistically significant.

\section{Results}

\section{APG-2449 elicits antitumor effect on ESCC cell lines via FAK signaling inhibition}

APG-2449 is a novel oral multi-kinase inhibitor and the chemical structure of APG-2449 is showed in Fig. 1A. Its main targets include ALK, ROS1, and FAK (Supplementary Table S1). However, as ALK and ROS1 are hardly expressed in ESCC and are not driver genes for ESCC, we speculated whether APG-2449 could exert anti-esophageal cancer effect by inhibiting FAK. To analyze the antitumor effect of APG-2449 in ESCC cell lines, the cell viability of a panel of six ESCC cell lines after treatment with APG-2449 was evaluated by CCK-8 assay. As shown in Fig. 1B and C, APG-2449 suppressed the cell viability of KYSE150 and KYSE-520 cells in a dose-dependent manner. Table 1 showed the $\mathrm{IC}_{50}$ values of six ESCC cell lines after treatment with APG-2449 for $72 \mathrm{~h}$, and the IC50 values ranging from 0.5-3 $\mu \mathrm{M}$. Besides, colony formation in KYSE-150 and KYSE520 cells were significantly decreased after treatment with APG-2449 for 14 days (Fig. 1D, E). Wound healing assays demonstrated that APG-2449 could inhibit the cell migration ability of ESCC cells (Fig. 1F, G). 
Table 1

The $\mathrm{IC}_{50}$ of APG-2449 in six ESCC cell

lines at 72 hours.

\begin{tabular}{|ll|}
\hline Cell lines & IC $_{50}$ of APG-2449 $(\mu \mathrm{M})$ \\
\hline YES-2 & $0.96 \pm 0.09$ \\
KYSE-150 & $2.31 \pm 0.17$ \\
KYSE-520 & $0.83 \pm 0.11$ \\
KYSE-510 & $2.27 \pm 0.40$ \\
TE-1 & $2.21 \pm 0.36$ \\
TE-10 & $2.60 \pm 0.51$ \\
\hline
\end{tabular}

To determine the mechanism of antitumor effect on ESCC cells by APG-2449, one of the most potential targets, the FAK signaling pathway were analyzed by Western blot after treatment with APG-2449. In KYSE-150 and KYSE-520 cells, which were treated with increasing concentration of APG-2449, the levels of phosphorylated FAK decreased, as well as that of the downstream marker AKT (Fig. 1H). Collectively, APG-2449 inhibited the ESCC cells proliferation and migration through the FAK blockade.

\section{APG-2449 synergistically enhances the antitumor effect of ibrutinib in ESCC cells}

Ibrutinib was reported to be a promising antitumor agent in ESCC patients with MYC and/or ERBB2 amplification. We then asked if the combination therapy of APG-2449 and ibrutinib could achieve a better antitumor effect in ESCC patients other than MYC and/or ERBB2 amplification. In order to verify our hypothesis, CCK-8 assays were carried out to test the cell viability after treatment with single-agent and combination. We found that both APG-2449 and Ibrutinib showed some inhibitory effect of cell viability, while the combination of APG-2449 and Ibrutinib significantly suppressed cell viability compared with single-agent in KYSE-150 and KYSE-520 cells for 24, 48 and 72 hours respectively (Fig. 2). The combination index $(\mathrm{Cl})$ also indicated a synergistic effect with a value less than 1 . Similar results were obtained in a panel of other ESCC cell lines including YES-2, KYSE510 and TE-10 cells (Supplementary Figure S1) This result suggested that APG-2449 could enhance the antiproliferation effect of ibrutinib in ESCC cell lines.

\section{Combination therapy of APG-2449 and ibrutinib inhibits ESCC cells proliferation and migration}

We next intended to detect the enhanced antitumor in vitro effect of APG-2449 and ibrutinib combination treatment in ESCC cells. First, we determined the colony formation of KYSE-150 and KYSE-520 cells after treatment with DMSO, APG-2449, ibrutinib and combination therapy. Both APG-2449 and ibrutinib were found to significantly impair colony formation ability, while the combination therapy led to a more dramatic decrease in colony numbers in KYSE-150 and KYSE-520 cells (Fig. 3A, B). Transwell assay demonstrated that both APG-2449 and ibrutinib slightly hampered the migration ability of KYSE-150 and 
YES-2 cells, the combination treatment had a much better inhibitory effect (Fig. 3C, D). Taken together, these results indicated that APG-2449 combined with ibrutinib significantly inhibit ESCC cells proliferation and migration.

\section{APG-2449 combined with ibrutinib synergistically induces ESCC cells cycle arrest and apoptosis}

The cell cycle distribution detection assays showed that ibrutinib caused a slight G1/G0 phase arrest compared to treatment with DMSO. APG-2449 could enhance ibrutinib to induce a more dramatic increase in G1/G0 phase arrest in KYSE-150 and KYSE-520 cells (Fig. 4A, B). APG-2449 and ibrutinib treatment alone for 72 hours could induce a slight increase in apoptosis in both KYSE-150 and KYSE-520 cells. However, the percentage of apoptosis cells in combination therapy were significantly increased compared to either agent alone (Fig. 4C, D). Considering that the apoptosis rate seems to be low detected in 72 hours after treatment, we also increased the duration of drug treatment to 5 days, but the proportion of cell apoptosis is still not high (data was not shown here), which indicated that combined effect of APG-2449 and ibrutinib does not mainly work by inducing apoptosis.

\section{APG2449 and ibrutinib combination treatment mediates AKT and MAPK pathways inhibition}

We found that the KYSE-520 cell, which harbors EGFR amplification but not MYC and/or ERBB2 amplification and reported to be resistant to EGFR-TKI, was sensitive to ibrutinib. First, we detected the basic protein expression of EGFR, p-EGFR and BTK in six ESCC cell lines. We found that KYSE-150 and KYSE-520 which had high level of EGFR expression and medium level BTK expression were more sensitive to ibrutinib than the TE10 and TE-1 cells which had higher BTK expression (Fig. 5A and Supplementary Fig. S2). And then we tested the cell cytotoxicity of two kinds of BTK inhibitor with ibrutinib and Acalabrutinib in KYSE-150 and KYSE-520 cells for $72 \mathrm{~h}$. We found that both KYSE-150 and KYSE-520 cells were less sensitive to Acalabrutinib compared to ibrutinib with the IC50 values higher than $15 \mu \mathrm{M}$ (Fig. 5B). We wondered why the sensitivity of ESCC cells to the two kinds of BTK inhibitors was so different. We next evaluated the EGFR and its downstream pathway protein expression in KYSE-520 cells treated with ibrutinib and Acalabrutinib respectively. We observed that the protein expression of phosphorylated EGFR, AKT, and ERK were nearly completely diminished after treatment with Ibrutinib at $1 \mu \mathrm{M}$, while slightly decreased in acalabrutinib treatment at $2 \mu \mathrm{M}$ (Fig. 5C). In order to confirm that ibrutinib mediated inhibition of EGFR signaling, we performed the knockdown of EGFR in KYSE- 520 cells by siRNA interference. The data revealed that the knockdown of EGFR could attenuated the sensitivity of KYSE-520 cells to Ibrutinib treatment, with the IC50 value increased up to 4-fold compared to the siNC (Fig. 5D-E). These results indicated that ibrutinib may also exert an antitumor effect by inhibiting EGFR signaling in ESCC.

To further illustrate the underlying mechanisms of APG-2449 and ibrutinib combination therapy, we performed a kinase proteome profile array which included 43 kinase phosphorylation sites in KYSE-150 cells with APG-2449 and ibrutinib treatment. The result indicated multiple kinases were active or inactive follow APG-2449, ibrutinib and combination treatment (Fig. 5F). Take into consideration the kinases that had the most significant changes and were more pivotal in esophageal cancer, we then focus on the 
effect on the downstream signaling of FAK and EGFR in KYSE-150 and KYSE-520 cells by western blotting. Our results demonstrated that the combination of ibrutinib and APG-2449 could dramatically downregulate the phosphorylated MEK, ERK and AKT expression compared to the single agents (Fig. 5G). And these changes were occurred within 3 hours after treatment (Supplementary Fig. S3). We also detected the expression of phosphorylated STAT3, but there was no significant change (data was not shown here). The above results indicated that underlying mechanism of the combination therapy of APG2449 and ibrutinib on ESCC may be through inhibiting the AKT and MAPK pathways.

\section{APG-2449 combined with ibrutinib significantly suppresses the growth of ESCC cells xenograft models}

To evaluate the antitumor effect of APG-2449 in vivo, KYSE-150 and KYSE-520 tumor cells xenograft models were established. Respective mice were treated with vehicle control or APG-2449 $(50 \mathrm{mg} / \mathrm{kg}$ and $100 \mathrm{mg} / \mathrm{kg}$ ) via oral gavage once a day for 2 weeks. APG-2449 significantly suppressed tumor growth in both KYSE-150 and KYSE- 520 models at $100 \mathrm{mg} / \mathrm{kg}$ compared to the vehicle control group, while the inhibitory effects of $50 \mathrm{mg} / \mathrm{kg}$ were limited (Fig. 6A, C). In addition, with the administration of APG-2449, no weight loss or any other sign of toxicity were observed in the two animal models, indicating that APG2449 was well-tolerated (Fig. 6B, D).

To further investigate whether APG-2449 and ibrutinib combination therapy could induce an enhanced antitumor effect in ESCC tumor in vivo, we established a KYSE-150 cells subcutaneous xenograft mouse model. When the tumor volume reached approximately $50 \mathrm{~mm}^{3}$, the mice were randomly assigned into four groups $(n=7)$ and received treatment with vehicle control, APG-2449, ibrutinib and combination of both agents for two weeks. As a single agent, $100 \mathrm{mg} / \mathrm{kg}$ of APG-2449 or $25 \mathrm{mg} / \mathrm{kg}$ of ibrutinib elicited similar partially inhibition on KYSE-150 tumor growth, whereas the combination of these agents produced a vastly better growth inhibition (Fig. 6E). The treatment of APG-2449 or ibrutinib alone induced $43 \%$ and $39 \%$ inhibition of tumor growth, respectively, while the combination of APG-2449 with ibrutinib induced $76 \%$ tumor growth suppression compared with vehicle control (Fig. 6E). In addition, no significant weight loss or other signs of toxicity were observed in any of the treatment groups (Fig. 6F). These results indicated that the combination of APG-2449 and ibrutinib has synergistic anticancer activity in vivo and is well tolerated.

\section{Discussion}

In this study, we demonstrated for the first time that a novel multi-kinase inhibitor APG-2449 can exert an effective antitumor effect in ESCC mainly through FAK signaling inhibition. In addition, APG-2449 combined with ibrutinib can achieve a potent antitumor effect in ESCC both in vivo and in vitro. The mechanism of the synergistic effect of combination therapy is mainly through down-regulating the EGFR and FAK signaling pathway.

As a single agent, APG-2449 could effectively inhibit the growth and migration of ESCC cells in vitro. In vivo experiments also showed that APG-2449 could inhibit tumor growth without significant toxic and 
side effects. However, the efficacy of APG-2449 as a monotherapy remains limited. Therefore, we further to verify the possible synergistic antitumor effect of APG-2449 in combination with another targeted drug, ibrutinib, which has recently been found to have a potential antitumor role in esophageal cancer. We found that the combination therapy of APG-2449 and ibrutinib could produce more effective antitumor activity in ESCC cells, including enhanced inhibition of cell proliferation, induction of apoptosis and cell cycle arrest. In exploring synergistic mechanisms, we confirmed the roles of APG-2449 in inhibiting the phosphorylation of FAK/AKT in both KYSE-150 and KYSE-520 cells. We also found that APG-2449 had no obvious effects on the phosphorylation of the MEK/ERK pathways. Interestingly, the combination of APG2449 and ibrutinib drastically inhibited the phosphorylation of MEK/ERK and AKT, the major downstream pathways of EGFR and FAK. Moreover, we found that the combination of APG-2449 and ibrutinib had a synergistic antitumor effect in ESCC in vivo model. Previous research shows that MAPK reactivation mediates resistance to EGFR inhibition, and CDK4 / 6 / MEK inhibition improves EGFR TKI in vivo response[23]. In mechanism, similar results can be achieved by combining APG-2449 and ibrutinib. To our knowledge, this is the first report to explore the combination therapy of FAK pathway blockade and ibrutinib in ESCC. However, we only took body weight as a parameter for the toxicity of the combination therapy. Whether the combination therapy would cause other toxicities still needs further evaluation. In addition, the combination therapy in vivo activity was evaluated in only one tumor model and more animal models or metastatic tumor models are still needed to verify the inhibitory effect of combination therapy on ESCC tumor growth and metastasis. Whether the mechanism of action observed in vitro would also be observed in in vivo remains to be investigated. FAK signaling is reported to be closely involved in the regulation of MDSCs, TAMs, and Tregs within the TME[24, 25]. BTK can regulate $B$ cell and macrophage-mediated T cell suppression in pancreatic adenocarcinoma[26]. And ibrutinib can restore Tcell-dependent antitumor immune responses, thereby inhibiting PDAC growth and improving chemotherapy responsiveness[18].Therefore, further investigation of APG-2449 and ibrutinib combination therapy in immunocompetent mouse tumor model may reveal possible interactions of APG-2449 and ibrutinib on tumor-immune microenvironment in treatment of ESCC. In addition, some researches show that FAK is closely related to the metastasis of esophageal cancer[13, 14, 27]. In our future experiments, we may need to further verify the effect of APG-2449 as a single drug and combined with ibrutinib on ESCC tumor metastasis.

Although the main role of BTK inhibitors is to block the B cell receptor pathway in malignant B cells, the indications for BTK inhibitors are expanded into non-hematological malignancies[18]. In EGFR-mutant NSCLC cells, ibrutinib can selectively inhibit cell growth and induce apoptosis by inhibiting EGFR signaling pathway $[20,28]$. Ibrutinib can potently inhibit the cell growth of ERBB2 ${ }^{+}$breast cancer cells via suppressing the ERBB2 receptor phosphorylation, and enhance the antitumor effect of dual PI3K/mTOR inhibitor BEZ235 in ERBB2 + breast cancer cells[21]. Besides, BTK has been identified as a novel candidate therapeutic target in esophageal cancer, and ibrutinib exerts a potent antitumor effect in patients with MYC and/or ERBB2 amplified advanced esophageal cancer[19, 29]. In our current study, we were surprised to find that ibrutinib also effectively inhibited the cell growth of those ESCC cells that do not have MYC and/or ERBB2 amplification. We wonder if the antitumor effect of ibrutinib can also be 
achieved by another BTK inhibitor, we applied a second-generation BTK inhibitor, Acalabrutinib, to test the antitumor effect in ESCC cell lines. However, we found that Acalabrutinib did not induce any growth inhibition in ESCC cell lines like ibrutinib. In addition, ibrutinib was found to dramatically inhibit the phosphorylation of EGFR, MEK/ERK and AKT in both KYSE-150 and KYSE-520 cells, while this phenomenon was not observed with the treatment of Acalabrutinib. Since MAPK and AKT are two of major EGFR downstream pathways, our results demonstrated that ibrutinib can induce anti-ESCC effect also by inhibiting EGFR signal. Inhibiting EGFR by siRNA interference attenuated the sensitivity of ESCC cell lines to ibrutinib treatment, further supporting the concept of ibrutinib-mediated EGFR-dependent antitumor effects. ESCC frequently show EGFR gene amplification and overexpression[30, 31]. However, the EGFR tyrosine kinase inhibitor show limited efficacy in ESCC treatment. Our findings may provide a new treatment strategy for EGFR-positive ESCC patients.

Collectively, our findings may provide a preclinical evidence for combination therapy of APG-2449 and ibrutinib in ESCC via inhibiting EGFR and FAK signaling, but still warrants further validation and clinical investigations.

\section{Declarations}

\section{Ethics approval and consent to participate}

All animal experiments were performed under the guidance of Sun Yat-Sen University Committee for Use and Care of Laboratory Animals and were approved by the animal experimentation ethics committee. Inform consent is not applicable.

\section{Consent for publication}

All the authors have read and approved the manuscript.

\section{Availability of data and material}

The key raw data have been deposited into the Research Data Deposit (http://www.researchdata.org.cn), with the Approval Number of RDDB2020000796 and the datasets used in this study are publicly available.

\section{Competing interests}

The authors declare that they have no competing interests.

\section{Funding}


This study was supported by National Natural Science Foundation of China (NSFC:81602066 and 81772587); Natural Science Foundation of Guangdong

\section{Authors' contributions}

LQY, ZSN and PWT carried out the main work and drafted the manuscript. LQY and YLQ carried out the western blot and immunohistochemistry, the in vivo study. SJ and YLQ performed the statistical analysis. ZL, QMZ and YDJ designed the study. All authors read and approved the final manuscript.

\section{Acknowledgements}

No.

\section{References}

1. Feng RM, Zong YN, Cao SM, Xu RH. Current cancer situation in China: good or bad news from the 2018 Global Cancer Statistics? Cancer Commun (Lond). 2019;39:22.

2. Siegel RL, Miller KD, Jemal A. Cancer Statistics. 2017. CA Cancer J Clin. 2017; 67:7-30.

3. Chen W, Zheng R, Baade PD, Zhang S, Zeng H, Bray F, Jemal A, Yu XQ, He J. Cancer statistics in China, 2015. CA Cancer J Clin. 2016;66:115-32.

4. Smyth EC, Lagergren J, Fitzgerald RC, Lordick F, Shah MA, Lagergren P, Cunningham D. Oesophageal cancer. Nat Rev Dis Primers. 2017;3:17048.

5. Giri S, Pathak R, Aryal MR, Karmacharya P, Bhatt VR, Martin MG. Incidence trend of esophageal squamous cell carcinoma: an analysis of Surveillance Epidemiology, and End Results (SEER) database. Cancer Causes Control. 2015;26:159-61.

6. Abnet CC, Arnold M, Wei WQ. Epidemiology of Esophageal Squamous Cell Carcinoma. Gastroenterology. 2018;154:360-73.

7. Liang H, Fan JH, Qiao YL. Epidemiology, etiology, and prevention of esophageal squamous cell carcinoma in China. Cancer Biol Med. 2017;14:33-41.

8. Yoon H, Dehart JP, Murphy JM, Lim ST. Understanding the roles of FAK in cancer: inhibitors, genetic models, and new insights. J Histochem Cytochem. 2015;63:114-28.

9. Roy-Luzarraga M, Hodivala-Dilke K. Molecular Pathways: Endothelial Cell FAK-A Target for Cancer Treatment. Clin Cancer Res. 2016;22:3718-24.

10. Sulzmaier FJ, Jean C, Schlaepfer DD. FAK in cancer: mechanistic findings and clinical applications. Nat Rev Cancer. 2014;14:598-610.

11. Lee BY, Timpson P, Horvath LG, Daly RJ. FAK signaling in human cancer as a target for therapeutics. Pharmacol Ther. 2015;146:132-49. 
12. Lv PC, Jiang AQ, Zhang WM, Zhu HL. FAK inhibitors in Cancer, a patent review. Expert Opin Ther Pat. 2018;28:139-45.

13. Luo ML, Zhou Z, Sun L, Yu L, Sun L, Liu J, Yang Z, Ran Y, Yao Y, Hu H. An ADAM12 and FAK positive feedback loop amplifies the interaction signal of tumor cells with extracellular matrix to promote esophageal cancer metastasis. Cancer Lett. 2018;422:118-28.

14. Miyazaki T, Kato H, Nakajima M, Sohda M, Fukai Y, Masuda N, Manda R, Fukuchi M, Tsukada K, Kuwano H. FAK overexpression is correlated with tumour invasiveness and lymph node metastasis in oesophageal squamous cell carcinoma. Br J Cancer. 2003;89:140-5.

15. Wang ML, Rule S, Martin P, Goy A, Auer R, Kahl BS, Jurczak W, Advani RH, Romaguera JE, Williams $\mathrm{ME}$, et al. Targeting BTK with ibrutinib in relapsed or refractory mantle-cell lymphoma. N Engl J Med. 2013;369:507-16.

16. Wilson WH, Young RM, Schmitz R, Yang Y, Pittaluga S, Wright G, Lih CJ, Williams PM, Shaffer AL, Gerecitano J, et al. Targeting B cell receptor signaling with ibrutinib in diffuse large B cell lymphoma. Nat Med. 2015;21:922-6.

17. Byrd JC, Furman RR, Coutre SE, Flinn IW, Burger JA, Blum KA, Grant B, Sharman JP, Coleman M, Wierda WG, et al. Targeting BTK with ibrutinib in relapsed chronic lymphocytic leukemia. N Engl J Med. 2013;369:32-42.

18. Campbell R, Chong G, Hawkes EA. Novel Indications for Bruton's Tyrosine Kinase Inhibitors, beyond Hematological Malignancies. Journal of Clinical Medicine. 2018; 7.

19. Chong IY, Aronson L, Bryant H, Gulati A, Campbell J, Elliott R, Pettitt S, Wilkerson P, Lambros MB, ReisFilho JS, et al. Mapping genetic vulnerabilities reveals BTK as a novel therapeutic target in oesophageal cancer. Gut. 2017.

20. Gao W, Wang M, Wang L, Lu H, Wu S, Dai B, Ou Z, Zhang L, Heymach JV, Gold KA, et al. Selective antitumor activity of ibrutinib in EGFR-mutant non-small cell lung cancer cells. J Natl Cancer Inst. $2014 ; 106$.

21. Grabinski N, Ewald F. Ibrutinib (ImbruvicaTM) potently inhibits ErbB receptor phosphorylation and cell viability of ErbB2-positive breast cancer cells. Invest New Drugs. 2014;32:1096-104.

22. Ichihara E, Westover D, Meador CB, Yan Y, Bauer JA, Lu P, Ye F, Kulick A, de Stanchina E, McEwen R, et al. SFK/FAK Signaling Attenuates Osimertinib Efficacy in Both Drug-Sensitive and Drug-Resistant Models of EGFR-Mutant Lung Cancer. Cancer Res. 2017;77:2990-3000.

23. Zhou J, Wu Z, Wong G, Pectasides E, Nagaraja A, Stachler M, Zhang H, Chen T, Zhang H, Liu JB, et al. CDK4/6 or MAPK blockade enhances efficacy of EGFR inhibition in oesophageal squamous cell carcinoma. Nat Commun. 2017;8:13897.

24. Lim ST. Nuclear FAK: a new mode of gene regulation from cellular adhesions. Mol Cells. 2013;36:16.

25. Jiang H, Hegde S, Knolhoff BL, Zhu Y, Herndon JM, Meyer MA, Nywening TM, Hawkins WG, Shapiro IM, Weaver DT, et al. Targeting focal adhesion kinase renders pancreatic cancers responsive to checkpoint immunotherapy. Nat Med. 2016;22:851-60. 
26. Gunderson AJ, Kaneda MM, Tsujikawa T, Nguyen AV, Affara NI, Ruffell B, Gorjestani S, Liudahl SM, Truitt M, Olson P, et al. Bruton Tyrosine Kinase-Dependent Immune Cell Cross-talk Drives Pancreas Cancer. Cancer Discov. 2016;6:270-85.

27. Zhao X, Guan JL. Focal adhesion kinase and its signaling pathways in cell migration and angiogenesis. Adv Drug Deliv Rev. 2011;63:610-5.

28. Hu J, Zhang H, Cao M, Wang L, Wu S, Fang B. Auranofin Enhances Ibrutinib's Anticancer Activity in EGFR-Mutant Lung Adenocarcinoma. Mol Cancer Ther. 2018;17:2156-63.

29. Wang Y, Cheng J, Xie D, Ding X, Hou H, Chen X, Er P, Zhang F, Zhao L, Yuan Z, et al. NS1-binding protein radiosensitizes esophageal squamous cell carcinoma by transcriptionally suppressing c-Myc. Cancer Commun (Lond). 2018;38:33.

30. Fichter CD, Timme S, Braun JA, Gudernatsch V, Schopflin A, Bogatyreva L, Geddert H, Faller G, Klimstra D, Tang L, et al. EGFR, HER2 and HER3 dimerization patterns guide targeted inhibition in two histotypes of esophageal cancer. Int J Cancer. 2014;135:1517-30.

31. Jiang D, Li X, Wang H, Shi Y, Xu C, Lu S, Huang J, Xu Y, Zeng H, Su J, et al. The prognostic value of EGFR overexpression and amplification in Esophageal squamous cell Carcinoma. BMC Cancer. 2015;15:377.

\section{Figures}


A

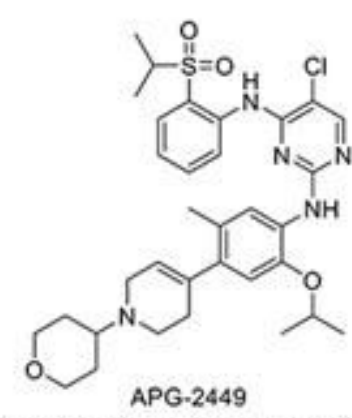

Chemical Formula: $\mathrm{C}_{33} \mathrm{H}_{42} \mathrm{CIN}_{5} \mathrm{O}_{4} \mathrm{~S}$ Exact Mass: 639
B

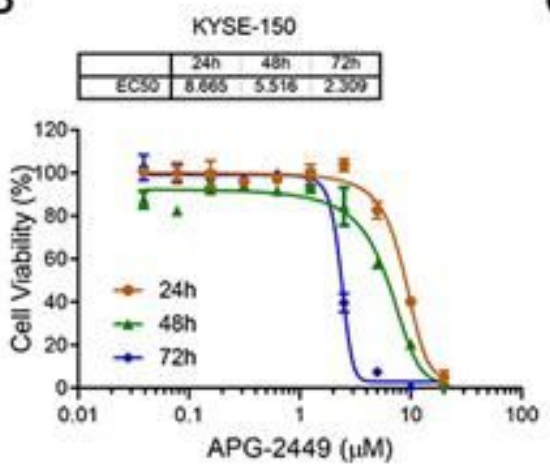

C

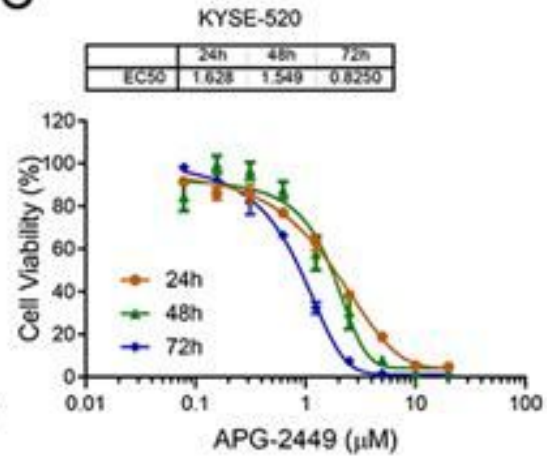

D

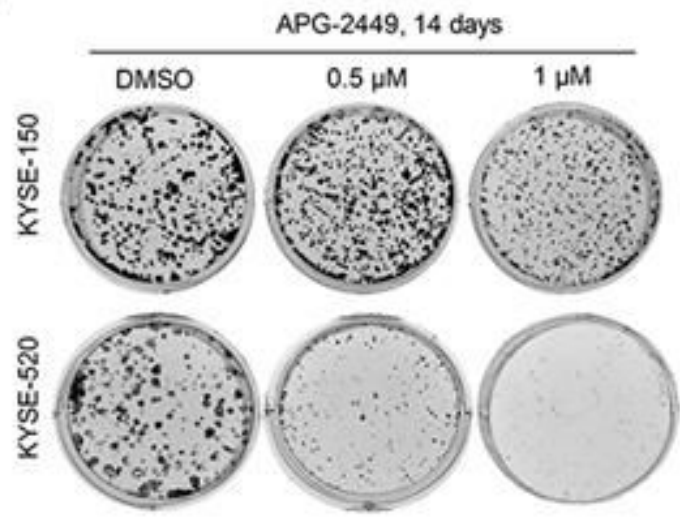

$E$

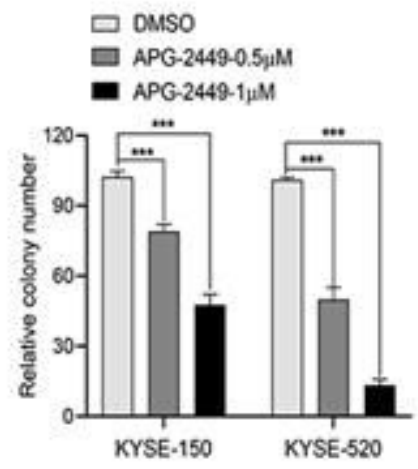

$\mathrm{F}$
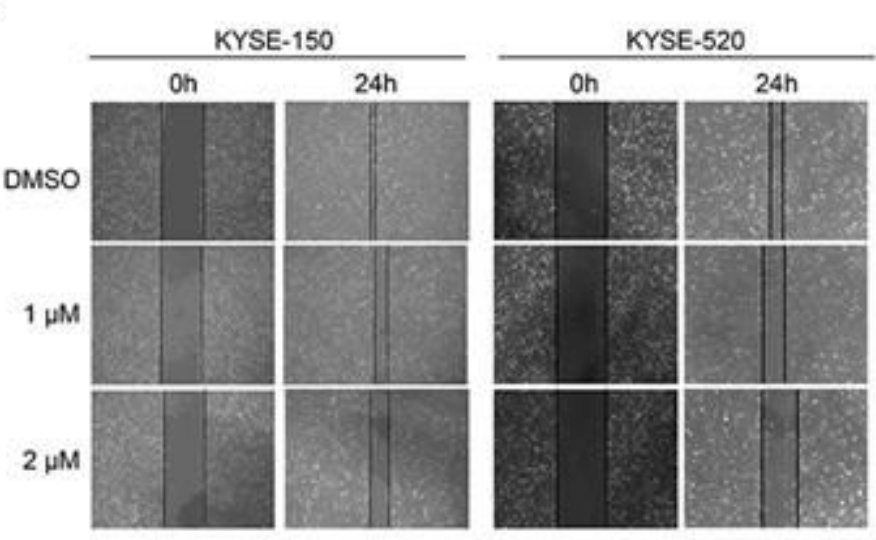

$\mathrm{H}$

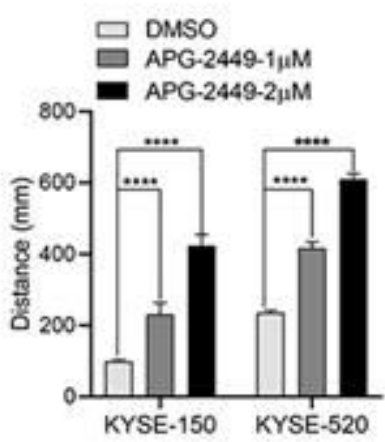

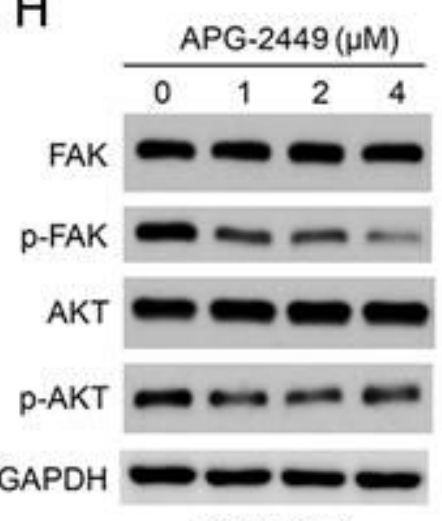

KYSE-150

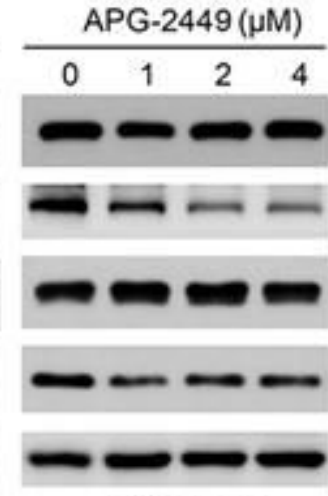

KYSE-520

\section{Figure 1}

APG-2449 inhibit ESCC cells proliferation and migration. A. The chemical structure of APG-2449. B. Cell viability was measured by CCK-8 after incubated with the indicated dose of APG-2449 for 24, 48 and 72 hours in KYSE-150 cells. C. Cell viability was measured by CCK-8 after incubated with the indicated dose of APG-2449 for 24, 48 and 72 hours in KYSE-520 cells. D. Representative images of colony formation of the indicated cells cultured with APG-2449 at different concentrations for 14 days. E. Quantification of colony formation of the indicated cells cultured with APG-2449 at different concentrations for 14 days. F. Representative images of migration by wound healing assay of the KYSE- 150 cells treated with APG2449 at different concentrations for 24 hours. G. Quantification of migration by wound healing assay of the KYSE-150 cells treated with APG-2449 at different concentrations for 24 hours. H. Western blot 
analysis of FAK/AKT signaling change in KYSE-150 and KYSE-520 cells treated with APG-2449 at indicated dose for 24 hours. GAPDH was used as a loading control. Data in (E) and (G) are presented as mean \pm SD. derived from three individual experiments with triplicate wells. ${ }^{\star *} P<0.01 ; \star \star \star P<0.001$.
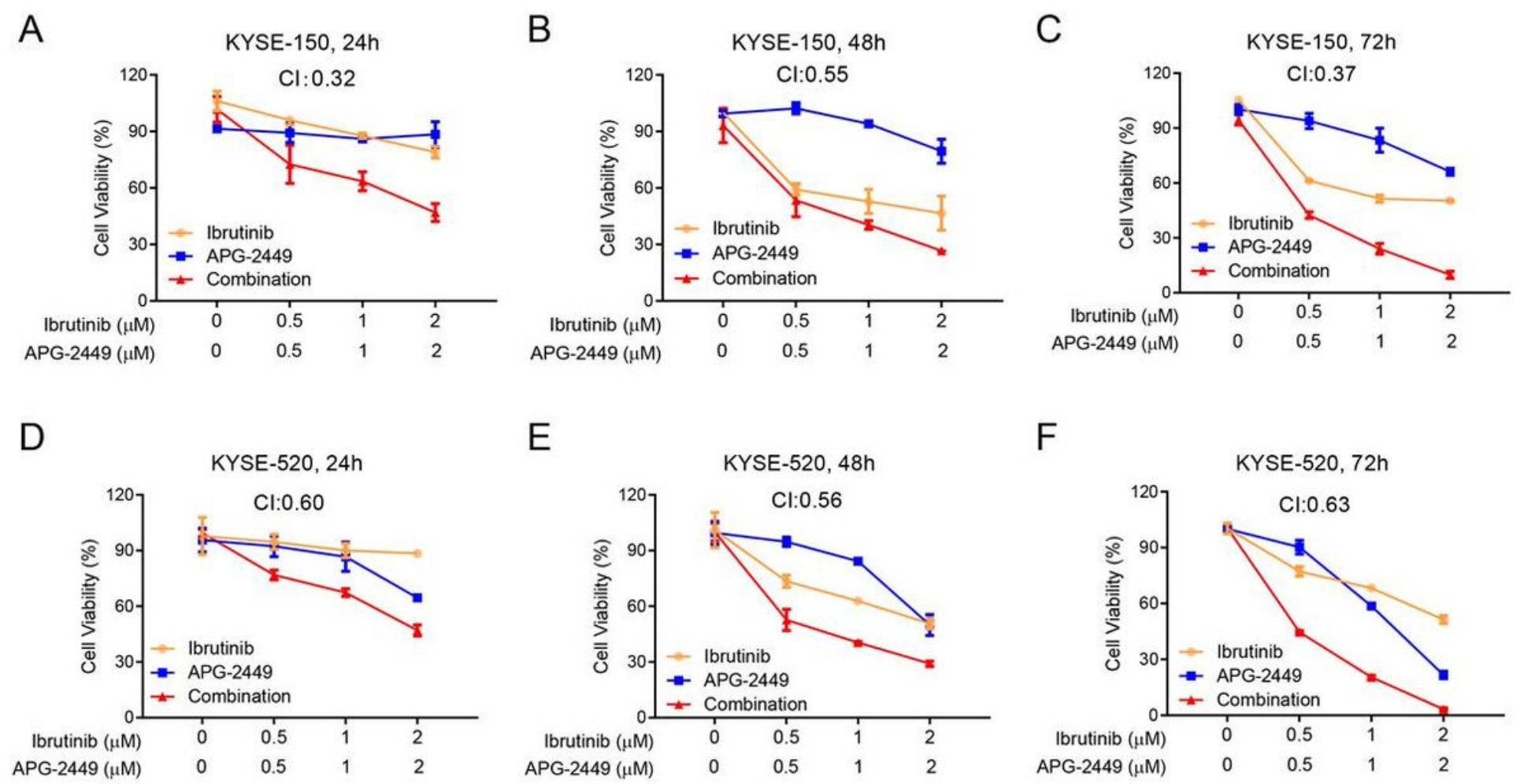

Figure 2

Synergistic effect between APG-2449 and ibrutinib in KYSE-150 and KYSE-520 cells in vitro. A. Cell viability of KYSE-150 cells after treated with APG-2449, ibrutinib, or the combination at indicated concentration for 24 hours. B. Cell viability of KYSE-150 cells after treated with APG-2449, ibrutinib, or the combination at indicated concentration for 48 hours. C. Cell viability of KYSE- 150 cells after treated with APG-2449, ibrutinib, or the combination at indicated concentration for 72 hours. D. Cell viability of KYSE520 cells after treated with APG-2449, ibrutinib, or the combination at indicated concentration for 24 hours. E. Cell viability of KYSE-520 cells after treated with APG-2449, ibrutinib, or the combination at indicated concentration for 48 hours. F. Cell viability of KYSE-520 cells after treated with APG-2449, ibrutinib, or the combination at indicated concentration for 72 hours. Data are presented as mean \pm SD. derived from three individual experiments with triplicate wells. Combination index (Cl) value was calculated by CalcuSyn software at ED50. If the $\mathrm{Cl}$ value is less than 1 , there is a synergistic effect 
A

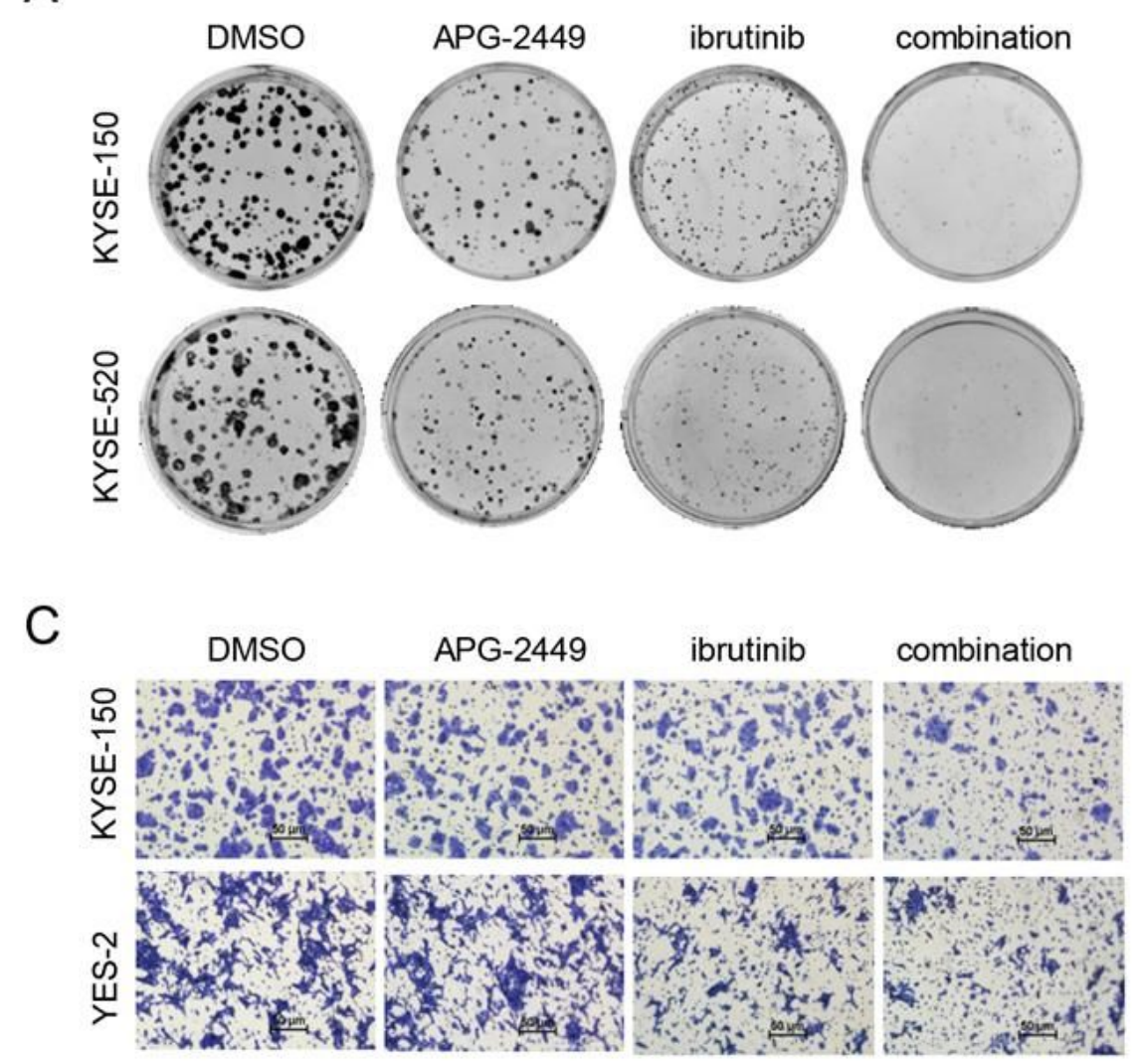

B
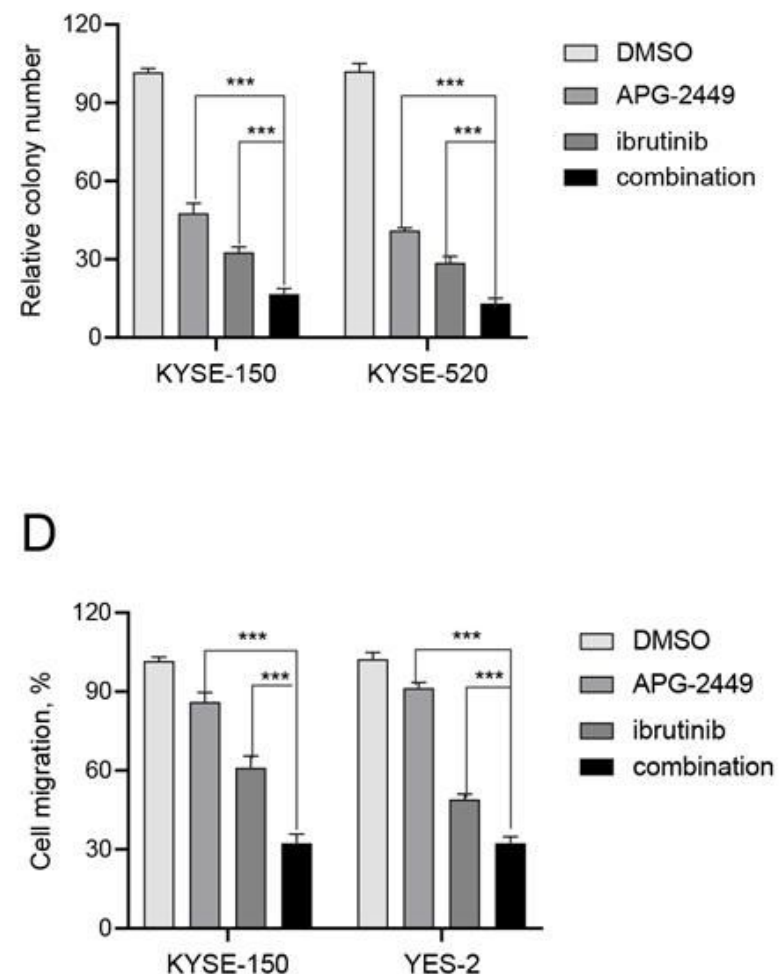

\section{Figure 3}

APG-2449 combined with ibrutinib significantly inhibited ESCC cells proliferation and migration. A. Representative images of colony formation of cells treated with $1 \mu \mathrm{M}$ APG-2449, $0.1 \mu \mathrm{M}$ (KYSE-520) to $0.5 \mu \mathrm{M}$ (KYSE-150) ibrutinib or both for 14 days. B. Quantification of colony number of colony formation assay in KYSE-520 and KYSE-150 cells. C. Representative images of migration assays in KYSE-150 and YES-2 cells treated with APG-2449 $(1 \mu \mathrm{M})$, ibrutinib $(1 \mu \mathrm{M})$ or both for24 h. D. Quantification of migration assays in KYSE-150 and YES-2 cells. Data in (B) and (D) are presented as mean \pm SD. derived from three individual experiments with triplicate wells. ${ }^{\star \star *} \mathrm{P}<0.001$. 
A
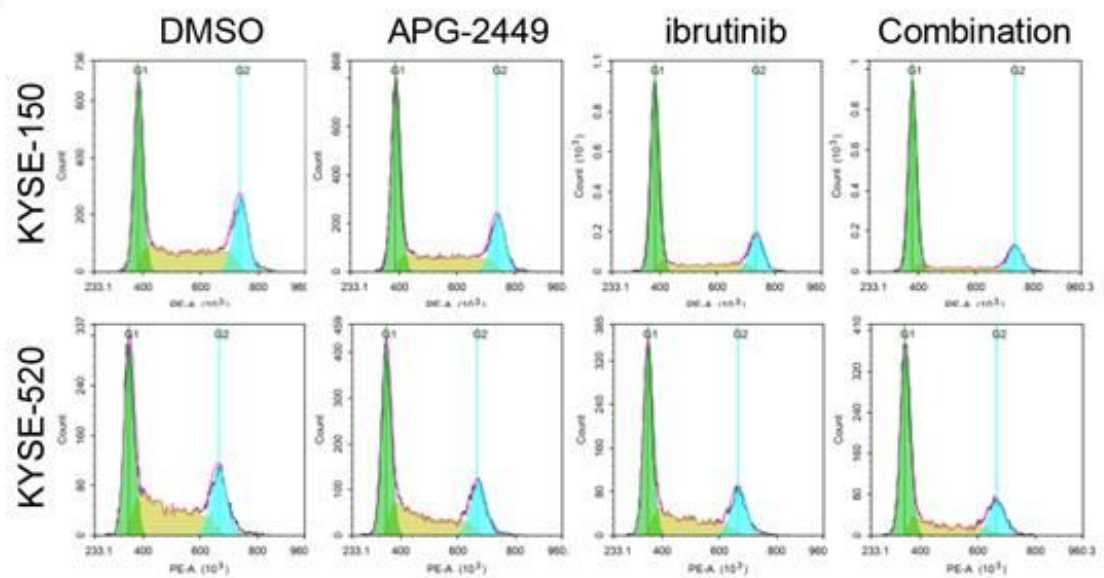

B

C
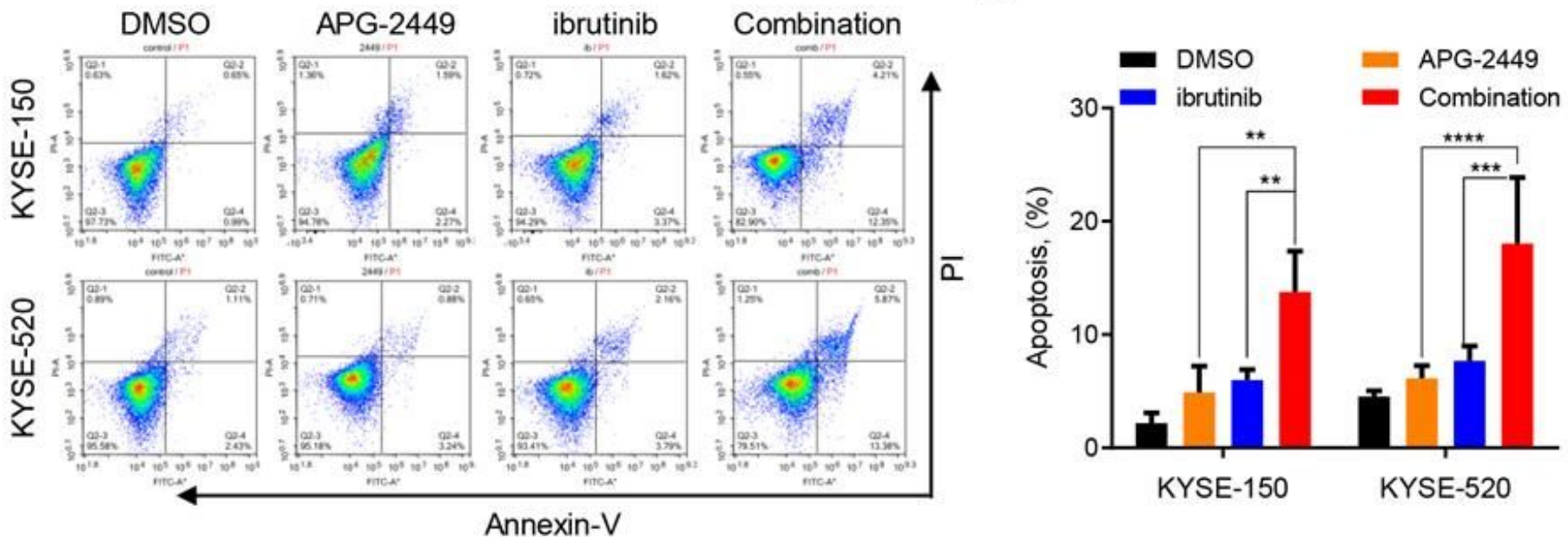

Figure 4

APG-2449 combined with ibrutinib significantly induced ESCC cells cycle arrest and apoptosis. A.

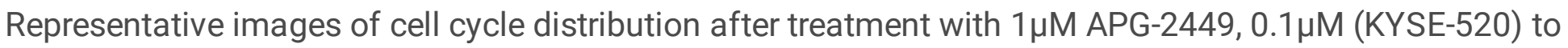
$0.5 \mu \mathrm{M}$ (KYSE-150) ibrutinib or both for 24 hours. B. Quantification of cell cycle distribution in KYSE-520 and KYSE-150 cells. C. Representative images of cell apoptosis detected by Annexin-V/PI assays of KYSE-150 and KYSE-520 cells treated with APG-2449 $(1 \mu \mathrm{M})$, ibrutinib $(1 \mu \mathrm{M})$ or both for 72 hours. D. Quantification of cell cycle distribution in KYSE-520 and KYSE-150 cells. Data in (D) are presented as mean \pm SD. derived from three individual experiments with triplicate wells. ${ }^{\star \star} P<0.01 ; \star \star \star P<0.001 ; * \star \star \star P$ $<0.0001$. 


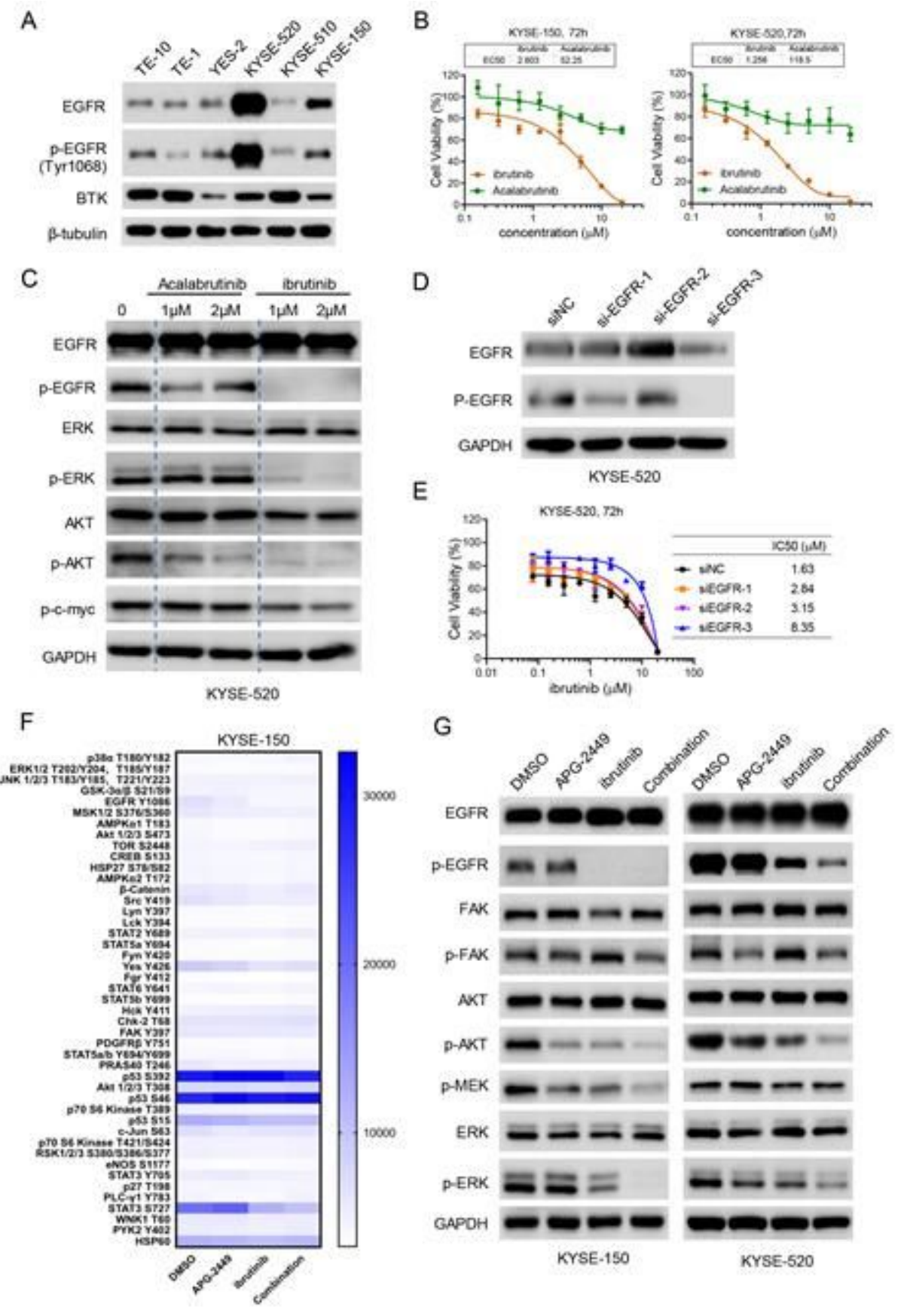

\section{Figure 5}

Effects of APG-2449 and ibrutinib on FAK and EGFR downstream signaling pathways. A. Basic protein expression of EGFR, p-EGFR and BTK in ESCC cell lines. B-tubulin was used as a loading control. B. Cell viability was measured by CCK-8 after incubated with the indicated dose of ibrutinib and Acalabrutinib for 72 hours in KYSE-150 and KYSE-520 cells. C. Western blot analysis of EGFR/ERK/AKT signaling change in KYSE-520 cells treated with ibrutinib or Acalabrutinib at indicated dose for 24 hours. D. Western blot analysis of the EGFR knockdown effect in KYSE-520 cells by siRNA assay. E. Cell proliferation was measured by CCK-8 in KYSE-520 cells with EGFR knockdown after incubated with ibrutinib at indicated dose for 72 hours. F. The Kinase Proteome Profile was performed to detect the effects of APG-2449, ibrutinib and combination treatment on downstream kinases in KYSE-150 cells. G. Western blot analysis 
of proteins level on FAK and EGFR downstream signaling pathways in KYSE-150 and KYSE-520 cells treated with DMSO, APG-2449, ibrutinib, or both for 24 hours. GAPDH was used as a loading control. Data in (B) and (E) are presented as mean \pm SD. derived from three individual experiments with triplicate wells.

A

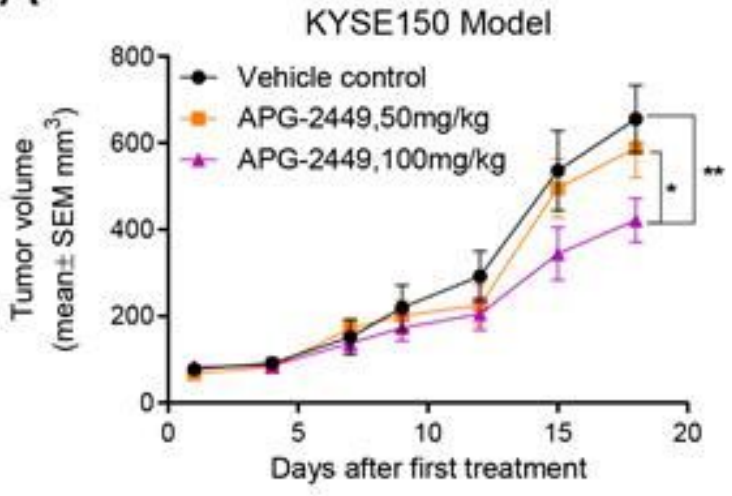

C

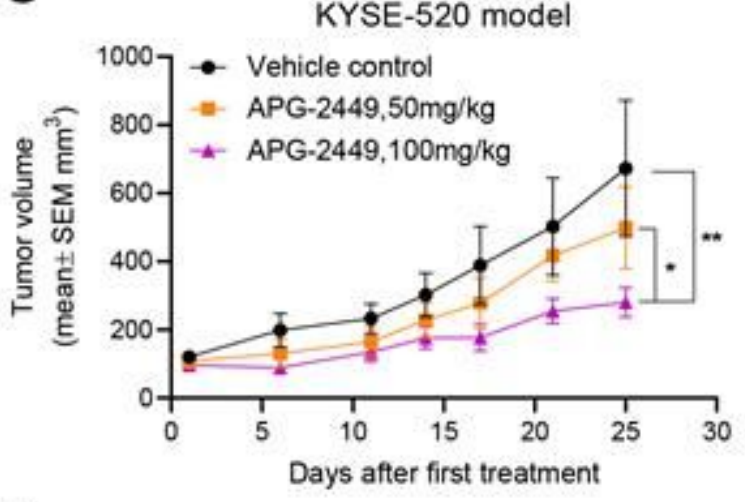

$E$

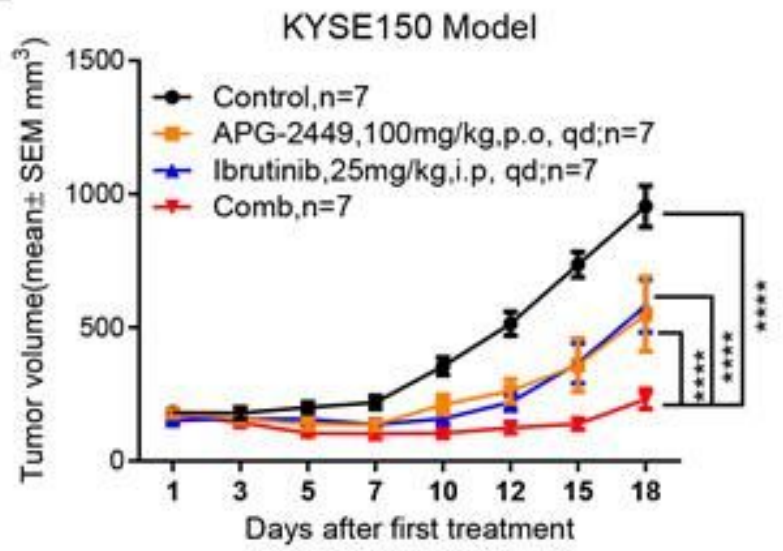

B

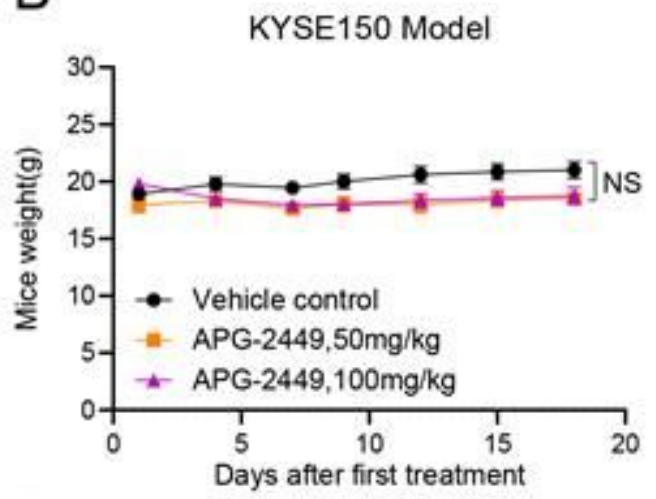

D

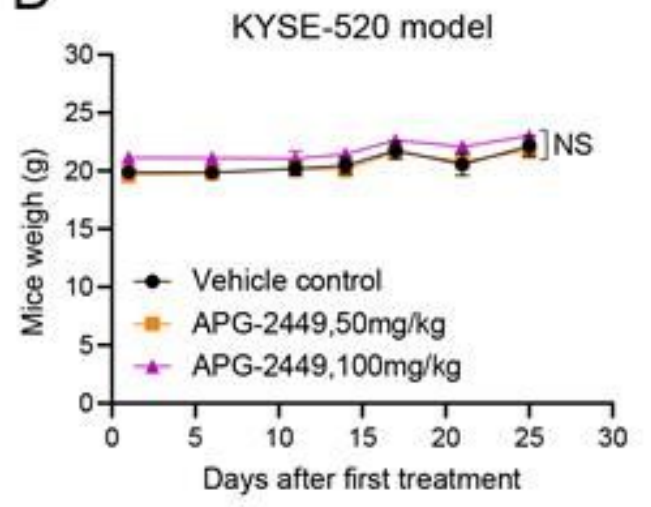

$\mathrm{F}$

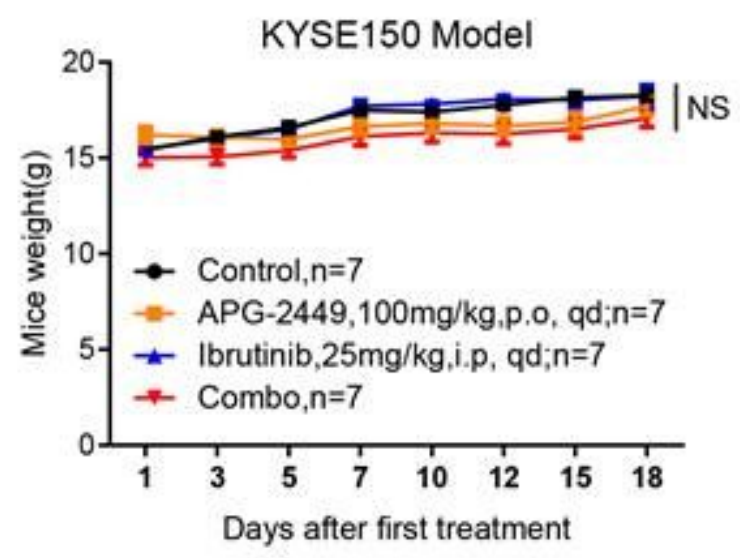

Figure 6

APG-2449 suppress ESCC cells in vivo and enhance the antitumor effect of ibrutinib in vivo A. KYSE-150 cells were subcutaneously inoculated into the dorsal flank of nude mice before they were treated with a vehicle or APG-2449 $(50 \mathrm{mg} / \mathrm{kg}$ and $100 \mathrm{mg} / \mathrm{kg})$ via daily oral gavage for 2 weeks. Tumor volumes were measured at indicated days. Data are shown as mean \pm SEM. of five mice in each group. B. Weight of the mice was recorded. Data are shown as mean \pm SEM of five mice in each group. C. KYSE-520 cells were subcutaneously inoculated into the dorsal flank of nude mice before they were treated with vehicle or 
APG-2449 $(50 \mathrm{mg} / \mathrm{kg}$ and $100 \mathrm{mg} / \mathrm{kg})$ via daily oral gavage for 2 weeks. Tumor volumes were measured at indicated days. Data are shown as mean \pm SEM of four mice in each group. D. Weight of the mice was recorded. Data are shown as mean \pm SEM of four mice in each group. E. KYSE-150 cells were subcutaneously inoculated into the dorsal flank of nude mice before they were treated with vehicle, APG2449 (100 mg/kg/day; by oral), ibrutinib ( $25 \mathrm{mg} / \mathrm{kg} /$ day; by intraperitoneal), or both. Tumor volumes were measured at indicated days. Data are shown as mean \pm SEM. of seven mice in each group. F. Mice weight of four separate groups was recorded. Data are shown as mean \pm SEM. of seven mice in each group. ${ }^{*} p<0.05,{ }^{\star \star} p<0.01$ and ${ }^{\star \star \star *} \mathrm{P}<0.0001$. versus corresponding control. NS, no significant.

\section{Supplementary Files}

This is a list of supplementary files associated with this preprint. Click to download.

- Supplementarydata.docx

- Supplementarydata.docx 